\title{
ÁREAS DE URBANIZAÇÃO ESPECIAL: AS POSSIBILIDADES E OS ENTRAVES NA IMPLEMENTAÇÃO DE NOVOS INSTRUMENTOS DE PLANEJAMENTO URBANO EM FLORIANÓPOLIS
}

Marina Toneli Siqueira ${ }^{1}$ Carolina Schleder ${ }^{2}$ Isabella Magnanti ${ }^{3}$

Resumo: O objetivo deste artigo é analisar as Áreas de Urbanização Especial (AUEs), zonas previstas no Plano Diretor de Florianópolis de 2014 nas quais a intenção de preservação ambiental alia-se ao adensamento e à criação de novas centralidades. A partir da análise do processo de elaboração do Plano Diretor, seu conteúdo normativo e decretos posteriores, bem como do levantamento de dados quantitativos e qualitativos, foi encontrado um cenário de dificuldades na formulação e aplicação do instrumento. Enquanto a legislação é vaga com relação aos benefícios e às contrapartidas esperadas, necessitando da formulação de projetos específicos, as AUEs já delimitadas apresentam uma diversidade de espacialidades e interesses envolvidos, configurando-se atualmente como áreas "congeladas" e de futuro incerto.

Palavras-chave: Preservação ambiental. Centralidades urbanas. Planos diretores. Instrumentos urbanísticos. Planejamento Urbano. Florianópolis/SC.

\section{SPECIAL URBANIZATION AREAS: THE POSSIBILITIES AND CONFLICTS OF IMPLEMENTING NEW URBAN PLANNING TOOLS IN FLORIANÓPOLIS}

Abstract: The purpose of this article is to analyze the Special Urbanization Areas (Áreas de Urbanização Especial, AUEs), zones established by the 2014 Masterplan of Florianópolis in which the objective of environmental preservation is combined with densification and the creation of new centralities. After the analysis of the Master Plan elaboration process, its normative content and subsequent decrees, as well as the collection of quantitative and qualitative data, a scenario permeated by difficulties in the formulation and application of the instrument was found. While the legislation is vague in terms of the expected benefits and counterparts, requiring the formulation of specific projects, the AUEs currently indicated expose a diversity of specialities and interests, currently acting as "frozen" areas and with an uncertain future.

Keywords: Environmental preservation. Urban centralities. Master Plans. Planning Instruments. Urban Planning. Florianópolis/SC.

\section{ÁREAS DE URBANIZACIÓN ESPECIAL: LAS POSIBILIDADES Y OBSTÁCULOS EN LA IMPLEMENTACIÓN DE NUEVOS INSTRUMENTOS DE PLANIFICACIÓN URBANA EN FLORIANÓPOLIS}

\footnotetext{
${ }^{1}$ Universidade Federal de Santa Catarina, Departamento de Arquitetura e Urbanismo, Florianópolis, Brasil, marina.siqueira@ufsc.br, https://orcid.org/0000-0002-1042-8743

2 Universidade de São Paulo, Departamento de Planejamento Urbano, São Paulo, Brasil, carolinaslschleder@gmail.com, https://orcid.org/0000-

0003-2918-6307

${ }^{3}$ Universidade Federal de Santa Catarina, Departamento de Arquitetura e Urbanismo, Florianópolis, Brasil, isamagnanti.arq@gmail.com,https://orcid.org/0000-0002-0274-8245
} 
Resumen: El propósito de este artículo es analizar las Áreas de Urbanización Especial (AUEs), zonas previstas en el Plan Maestro de Florianópolis de 2014, donde la intención de preservación ambiental se combina con la densificación y la creación de nuevas centralidades. A partir del análisis del proceso de elaboración del Plan Maestro, su contenido normativo y decretos posteriores, así como la recolección de datos cuantitativos y cualitativos, se encontrò um escenario de dificultades en la formulación y aplicación del instrumento. Si bien la legislación es vaga en relación a los beneficios esperados y contrapartes, requiriendo la formulación de proyectos específicos, las EAE ya delimitadas presentan una diversidad de espacios e intereses involucrados, configurándose actualmente como áreas "congeladas" con un futuro incierto.

Palabras clave: Preservación ambiental. Centralidades urbanas. Planos Maestros. Instrumentos de planificación urbana. Planeamiento urbanístico. Florianópolis/SC.

\section{Introdução}

Em 2014 foi aprovado um novo plano diretor para a capital catarinense. Passados dezessete anos de vigência do plano anterior, a nova lei de planejamento urbano de Florianópolis precisa lidar com um contexto socioespacial que foi drasticamente alterado nas últimas décadas pelo crescimento populacional, aumento da atividade turística e ocupação desordenada de um território ambientalmente rico e socialmente desigual. Como primeiro esforço de planejamento urbano após a aprovação do Estatuto da Cidade, o plano introduz os princípios da função social da cidade e de sua gestão democrática, que antes possuíam pouca ou quase nenhuma representatividade local. Florianópolis, entretanto, não difere de tantos outros municípios no país nos quais a esperança da aprovação de um novo quadro normativo com instrumentos sensíveis aos contextos locais, do estabelecimento e fortalecimento de instituições de planejamento urbano e da participação popular vêm enfrentando as dificuldades da política urbana brasileira. Esse trabalho explora 0 caso específico das Áreas de Urbanização Especial e suas potencialidades para o desenvolvimento urbano de Florianópolis.

Áreas de Urbanização Especial (AUEs) estão previstas no zoneamento do atual Plano Diretor de Florianópolis como forma de aliar a preservação ambiental, a urbanização social e a formação de novas centralidades. Em uma cidade com grande parte de sua área regulada como ocupação limitada e um histórico de desenvolvimento polinucleado, o novo plano procura enfrentar os problemas de mobilidade, degradação ambiental e dependência funcional do centro. Para tanto, propõe o adensamento de porções do território para a preservação do restante, estimulando usos mistos e humanizados. Ainda, prevendo estímulos para a 
implantação de projetos de interesse social, essas novas zonas enfrentariam a desigualdade social crescente em Florianópolis. Essa complexidade de interesses presentes nas AUEs, entretanto, parece estar longe de ser resolvida no formato da legislação vigente.

O presente trabalho demonstra que, após um longo e conflituoso processo que foi judicializado pelo Ministério Público devido à falta de participação popular, o Plano Diretor de Florianópolis (Lei Complementar 482 de 2014) possui partes contraditórias e instrumentos pouco definidos. Esse é justamente o caso das AUEs que, embora teoricamente demonstre a intenção de enfrentar a realidade territorial de Florianópolis, não possui uma definição clara de como seus ambiciosos objetivos serão efetivados, indicando a necessidade da elaboração de projetos específicos. Nesse sentido, está prevista a possibilidade de implantação de operações urbanas consorciadas nessas áreas. Por outro lado, este instrumento de parceria públicoprivada previsto pelo Estatuto da Cidade tem alcançado resultados polêmicos em suas experiências mais conhecidas em outras cidades brasileiras e levanta ainda mais dúvidas com relação ao futuro das AUEs em Florianópolis. Finalmente, em 2020 foram publicados decretos municipais que regulamentam as AUEs e os Planos Específicos de Urbanização (PEUs), mas ainda sem clareza nos benefícios e contrapartidas esperadas, abrindo espaço para discricionariedade e falta de transparência na aprovação dos mesmos.

O presente artigo procura, portanto, através da análise do caso específico das AUEs em Florianópolis, ter uma visão crítica sobre os potenciais e os limites dos planos diretores e instrumentos introduzidos nas cidades brasileiras após a aprovação do Estatuto da Cidade. Para tanto, foi realizado o estudo de bibliografia específica para traçar um histórico do processo de planejamento urbano da cidade, assim como a análise do texto normativo do Plano Diretor de 2014, seu processo de elaboração e o texto dos decretos municipais posteriores que regulamentam as AUEs $\mathrm{e}$ as vinculam ao funcionamento dos PEUs. Foi realizado também 0 levantamento de dados quantitativos e qualitativos acerca das AUEs, incluindo visitas e levantamentos in loco. Os dados foram processados e analisados, produzindo tabelas, quadros, mapas e textos.

Para expor os resultados alcançados, na primeira seção desse artigo, a cidade de Florianópolis é apresentada e contextualizada no histórico do planejamento urbano brasileiro. A segunda seção expõe o processo polêmico de desenvolvimento do Plano Diretor de 2014 e conceitua as AUEs. Para tanto, é 
utilizado o texto da lei, mapeadas as áreas zoneadas como AUEs e levantadas as suas principais características, demonstrando contradições e falta de clareza com relação aos seus objetivos. Por fim, na terceira seção, é utilizado o caso da AUE prevista no Distrito do Ribeirão da llha para demonstrar como o equilíbrio entre interesses privados, melhorias estruturais, preservação ambiental, patrimônio histórico e urbanização social necessitam do detalhamento de um projeto urbano específico para a área. Mesmo com a aprovação dos decretos municipais de 2020 que regulamentam as AUEs, ainda existe muita incerteza sobre 0 seu funcionamento e reais beneficiários. Como conclusão, é possível indagar se os objetivos propostos para as AUEs irão sair do papel uma vez que dependem de mais um ciclo de planejamento urbano em uma cidade que já é cenário de insegurança jurídica e incerteza entre os agentes da política urbana local.

\section{Buscando um sentido para as AUEs: uma cidade polinucleada e rica ambientalmente}

A Lei Federal 10.257 de 2001, conhecida como Estatuto da Cidade, e as legislações urbanísticas que emergem a partir da mesma, consolidam a preocupação com a produção do espaço nas cidades brasileiras. De fato, a história de nossa política urbana é muito diversa da história da nossa urbanização (Maricato, 2000; Villaça, 2004). Entre planos que não eram implementados e nem mesmo representavam a nossa realidade urbana, já que pareciam mais espelhar o contexto de países centrais do que nossa condição de semiperiferia do capitalismo, a verdadeira cidade brasileira era desconhecida. Atuar em nossa realidade urbana, portanto, significava (e ainda significa) ter que buscar as teorias e os instrumentos que lidem com a nossa ausência e/ou deficiência de infraestrutura, desigualdade e exclusão socioespacial, degradação de áreas ambientalmente sensíveis ou historicamente relevantes, bem como as irregularidades nos usos e ocupação do solo que atingem todas as faixas de renda, entre outros. Se a partir de 2001 uma nova agenda para a política urbana é consolidada normativamente na escala federal a partir do Estatuto da Cidade e regulações posteriores, a sua implementação nos municípios brasileiros e suas realidades socioespaciais concretas ainda é muito diversa e desigual.

Por um lado, é inegável que a promulgação do Estatuto da Cidade vem tendo um efeito direto no planejamento urbano ao expandir o debate sobre o direito à 
cidade e formalizar instrumentos que podem colocar em prática os princípios constitucionais da função social da propriedade e da regularização fundiária, como o Imposto Progressivo no Tempo e as Zonas Especiais de Interesse Social (Bassul, 2002; Maricato, 2000). Por outro, a primeira geração de planos diretores produzidos localmente demonstra dificuldades na compreensão desses instrumentos e de sua implementação, bem como de aderência aos princípios da gestão e planejamento democrático das cidades (Santos Jr. e Montandon, 2011). Para a presente pesquisa, interessa em especial aqueles instrumentos que procuram induzir proprietários e agentes imobiliários, negociando interesses públicos e privados em uma agenda de benefícios para a cidade como um todo. É nesse sentido que podemos analisar as Áreas de Urbanização Especial (AUEs) e o seu potencial para o desenvolvimento urbano de Florianópolis.

As AUEs são um tipo de zoneamento previsto no Plano Diretor de Florianópolis de 2014. De acordo com a Lei Municipal 482 de 2014, em seu artigo 42, elas são "grandes áreas urbanizáveis a partir de projeto amplo, que reserva setor predominante para preservação ambiental e adensa a área remanescente, criando novas centralidades caracterizadas pela mescla de funções e espaços humanizados" (PMF, 2014). Essa definição normativa expõe duas características fundamentais da cidade de Florianópolis que seu planejamento urbano atual pretende abarcar: a sua riqueza ambiental e a sua formação polinucleada.

Florianópolis, capital de Santa Catarina, está localizada no litoral do estado e possui o seu território dividido entre uma parte continental e outra insular. Com aproximadamente 42 praias, a sua costa é bastante recortada, com enseadas, baías, costões, pontas e lagoas. Embora com algumas planícies, a ilha é cortada por cristas montanhosas com morros de altitude acima dos 100 metros e diversas áreas consideradas de alta declividade. Dunas, manguezais, restingas e áreas alagáveis, entre outros, completam os diferentes ecossistemas que fazem com que a cidade seja conhecida por suas belezas naturais. Essa riqueza dos seus ecossistemas, por outro lado, faz com que boa parte do seu território seja considerado área de preservação permanente ou de ocupação limitada, restringindo as áreas passíveis de urbanização. Ainda, essa configuração natural influenciou diretamente na formação de uma cidade polinucleada.

Fundada na sua porção insular e primeiro ocupada militarmente para a defesa do território meridional brasileiro, Florianópolis possui um processo de ocupação lento e disperso (Veiga, 1993). O núcleo principal da Vila de Desterro desenvolveu- 
se a partir da atividade portuária enquanto o resto da ilha continuava praticamente desocupado até meados do século XVIII, quando a coroa portuguesa passou a estimular a migração de casais provenientes das llhas dos Açores. Recebendo estímulos fundiários e alguns equipamentos, esses novos moradores primeiro irão se estabelecer próximos à vila-sede e em caminhos que circundam o maciço central da cidade. A partir daí, a interiorização da ocupação significava a busca por terras férteis e pontos de fácil acesso, utilizando-se de caminhos existentes e da navegação marítima. Nessas "boas" localizações foram estabelecidas freguesias em áreas rurais e litorâneas, fundando comunidades praticamente autônomas. No entanto, o sistema de ocupação era claramente dominado pela Vila de Desterro como centralidade política, comercial e religiosa, além de possuir o maior número de habitantes da ilha (Peluso Junior, 1991).

Ainda, em contraste com a colonização portuguesa em outras regiões do país, baseada no grande latifúndio para exportação, a ocupação açoriana na llha de Santa Catarina foi caracterizada pela mão de obra familiar e pequenas propriedades. Os lotes eram demarcados pela sua testada, com limites perpendiculares a um caminho, a uma lagoa ou ao mar. No fundo desses lotes existiam áreas comunais, destinadas ao uso coletivo e com limites bastante imprecisos (Campos, 1991; Reis, 2002). Esse padrão de parcelamento do solo e o sistema polinucleado, com baixa conectividade e isolamento espacial, são aspectos ainda visíveis na Florianópolis contemporânea, mesmo com a ação do planejamento urbano tendo iniciado na cidade ainda na década de 1950.

O primeiro plano diretor de Florianópolis foi aprovado em 1955 e trazia o que havia de mais atualizado no urbanismo daquele momento, adotando os cânones racionalistas e progressistas do modernismo (Rizzo, 1993). O plano realizava uma revisão histórica, um diagnóstico dos problemas da cidade e um projeto para a sua planificação (Paiva; Ribeiro; Graeff, 1952). Objetivando retirar a cidade do atraso, o plano previu um porto na área continental, um centro universitário e o desenvolvimento da atividade turística. O principal eixo de desenvolvimento ainda estava na antiga vila-sede, em uma via expressa que conectava o continente e a península central, onde estaria localizado um centro de governo em estilo modernista. A sua implantação, entretanto, foi bastante limitada, restando majoritariamente aquelas intervenções de caráter rodoviário enquanto seu zoneamento foi bastante alterado ao longo do tempo (Pereira, 2000). 
Assim como o plano anterior, o esforço de planejamento urbano da cidade na década de 1970 focava majoritariamente na porção central da cidade. Nesse caso, o Plano de Desenvolvimento Integrado da Área Metropolitana de Florianópolis (Lei 1440/76) procurava o desenvolvimento da capital como forma de polarizar e integrar todo o estado de Santa Catarina (Rizzo, 1993). Dessa forma, propunha-se a criação de um centro administrativo, institucional e financeiro da área metropolitana na Baía Sul no distrito central e se estimulava a atividade turística, abarcando o território das freguesias na orla leste da ilha, em especial na antiga Freguesia de Nossa Senhora da Conceição da Lagoa. Mais uma vez, a principal contribuição do plano foram as intervenções viárias, acessando o interior da ilha e conectando a cidade com o resto do país através de rodovias estaduais e federais.

Durante as décadas de 1960 e 1970, portanto, foram construídas vias ligando os balneários norte e leste da ilha, pontes e rodovias de conexão ilha-continente e a emblemática avenida de contorno norte, a Avenida Beiramar Norte (Sugai, 1994). Além disso, a construção do campus da Universidade Federal de Santa Catarina, bem como de outros órgãos públicos, em área ainda bastante desabitada e de ocupação rural, impulsionou o crescimento do núcleo central da cidade em direção à antiga Freguesia da Nossa Senhora da Trindade. Finalmente, a partir da década de 1970, e em especial durante os anos 1980, aumentaram os empreendimentos imobiliários, em especial de caráter turístico nas regiões norte e nordeste da ilha ao mesmo tempo em que o próprio Estado investia em infraestrutura e serviços nessas áreas, impulsionando a ocupação e exploração dos atributos naturais da cidade.

Não é à toa, portanto, que nas próximas décadas são aprovados planos fragmentados para a cidade de Florianópolis. A Lei da Trindade (Lei Municipal 1.851/82) e o Plano Diretor dos Balneários (Lei Municipal 2.193/85) tratam da expansão da ocupação da ilha, enquanto esse último dava incentivos aos empreendimentos turísticos (Reis, 2002). Ainda, em 1997 foi aprovado o Plano Diretor de Florianópolis (Lei Municipal 01/97). Enfocando ainda muito dos seus investimentos no Distrito Sede, esse planejamento reforça o contraste entre núcleo central e balneários enquanto não prevê mais a integração metropolitana há muito concebida, mas pouco investida. $O$ plano foi bastante criticado pela sua permissividade à verticalização; falta de previsão de equipamentos, infraestrutura e serviços básicos; e abstenção em relação à sustentabilidade ambiental, mesmo em um território com ecossistemas tão frágeis, como já mencionado (Pimenta, 2005). Enquanto isso, os impactos negativos do crescimento acelerado da cidade são 
sentidos na ocupação desordenada, na falta de conexão entre bairros e aumento dos problemas de mobilidade, na degradação do meio ambiente e na desigualdade socioespacial. Em 2006, no último ano do prazo dado pelo Estatuto da Cidade para elaboração e adequação dos planos diretores municipais, iniciou-se um novo ciclo de planejamento urbano que pretendia lidar com essas problemáticas locais.

\section{O plano diretor de 2014 e as AUEs: finalmente um plano para a cidade como um todo?}

Observando o material disponibilizado pelo Instituto de Planejamento Urbano de Florianópolis (IPUF) sobre a elaboração do Plano Diretor do Município de Florianópolis de 2014 (PDMF), é possível perceber uma inversão na interpretação sobre a estrutura polinucleada da cidade. Ao invés de buscar a integração do território majoritariamente a partir de grandes obras viárias, como nos planos anteriores, o novo objetivo traçado é estimular a formação de novas centralidades e diminuir a dependência do centro tradicional no Distrito Sede. É justamente nesse sentido que podemos compreender o objetivo na formulação das AUEs.

O PDMF de 2014 é o primeiro plano diretor desenvolvido para Florianópolis após a aprovação do Estatuto da Cidade. Buscando a sua adequação ao mesmo e, em especial, cumprindo a imposição da elaboração/revisão de planos diretores para municípios com mais de 20 mil habitantes em um prazo de cinco anos, a Prefeitura de Florianópolis (PMF) inicia o processo de planejamento em 2006. Neste mesmo ano, ocorreu a definição do Núcleo Gestor, órgão colegiado de caráter consultivo e deliberativo, composto por representantes da sociedade civil e do poder público com a função de acompanhar a elaboração do plano e garantir a participação popular (CUNHA, 2013). Foram criados também os Núcleos Distritais que puderam levantar e apontar as principais demandas dos 12 distritos da cidade, em especial através da atuação das associações de bairro locais 4 .

Embora com críticas com relação à organização, o processo de participação com atividades locais foi continuado até 2008, culminando na formulação de diretrizes comunitárias. Porém, tanto o núcleo gestor quanto os núcleos distritais foram desmantelados no ano seguinte, quando uma empresa estrangeira foi

\footnotetext{
${ }^{4}$ É importante ressaltar que essas associações, embora algumas com maior intensidade do que outras, têm um histórico de forte atuação no desenvolvimento da política urbana em Florianópolis, inclusive com casos de propostas alternativas ao planejamento oficial da cidade tendo sido elaboradas a partir de iniciativas próprias, como no caso do Campeche (RIZZO, 2013).
} 
contratada para finalizar a produção do PDMF, que prosseguiu sem participação popular direta apesar da afirmação da Prefeitura de que as diretrizes comunitárias seriam mantidas (CUNHA, 2013). A população foi novamente incluída na elaboração do plano em 2009 mas, de acordo com Saboya, as sugestões não foram discutidas e/ou deliberadas conjuntamente ao longo desse período, já que "os técnicos no máximo rebatiam um ou outro argumento com colocações imprecisas, e não havia nenhum procedimento para aprofundamento dos pontos de vista" (SABOYA, 2010).

Finalmente, o anteprojeto do PDMF foi apresentado pela Prefeitura e levado à Câmara de Vereadores para aprovação em 2010. Porém, devido às manifestações de desacordo da população com relação ao seu processo de elaboração, a tramitação foi estagnada (CUNHA, 2013). O plano foi retomado apenas em 2012 , com a eleição de um novo governo e a contratação de uma nova equipe para coordenar o processo junto ao IPUF, reformulando o plano em quase toda a sua integridade. Em 2013, a nova gestão à frente da Prefeitura tentou cumprir a promessa de campanha e aprovar o plano ainda no primeiro ano de governo, seguindo com o novo projeto de lei para ser discutido na Câmara de Vereadores. Após nova judicialização do processo com uma ação civil do Ministério Público Federal e da negociação de mais de 600 emendas, a Lei 482 é aprovada em janeiro de 2014 com 305 emendas ao texto original.

O processo, entretanto, não se encerrou aí, já que a falta de participação popular gerou mais uma ação do Ministério Público Federal e a obrigatoriedade da continuidade do ciclo de planejamento urbano com a elaboração de novas audiências públicas (SIQUEIRA, GONÇALVES, CHAVES, 2020). Em meio às novas atividades e após a elaboração de quatro minutas para a lei, em 2017, e após novo recurso da Prefeitura, tem-se a determinação do Supremo Tribunal de Justiça de que o plano vigente para Florianópolis é aquele aprovado em 2014 em meio à grande instabilidade política e jurídica. De qualquer forma, o processo tumultuado de elaboração do Plano Diretor de 2014 transparece em seu texto de lei, com partes contraditórias, instrumentos pouco definidos e seções simplesmente inexistentes. Este é justamente o caso das AUEs.

Como mencionado anteriormente, as AUEs são definidas como "grandes áreas urbanizáveis a partir de projeto amplo, que reserva setor predominante para preservação ambiental e adensa a área remanescente, criando novas centralidades caracterizadas pela mescla de funções e espaços humanizados" (PMF, 2014). As AUEs são consideradas um zoneamento pertencente às Macro Áreas de Transição 
que, conforme sua denominação, almejam criar uma zona de amortecimento entre a cidade consolidada e as áreas não urbanizadas. Dessa forma, as AUEs estão próximas tanto de regiões com certo grau de urbanização - necessário para a criação de novas centralidades -, quanto de partes da cidade ainda pouco ocupadas e que necessitam de diretrizes para o seu desenvolvimento. Ademais, fica confirmado o caráter da AUE que, ao mesmo tempo em que prioriza a preservação ambiental de partes do território, possibilita a concentração de usos em seu restante.

As contradições começam a se evidenciar quando as AUEs aparecem novamente no texto da lei como um tipo de Área Especial de Intervenção Urbanística (AEIU), consideradas pelo PD como áreas a serem sobrepostas ao zoneamento, e não como um zoneamento por si só. As AEIUs podem trazer usos e atividades com regras específicas e que viriam a prevalecer sobre as zonas originais, com o objetivo de viabilizar intervenções de interesse municipal. Dos 11 tipos de AEIUs apresentadas, entretanto, apenas a AUE carece de uma seção específica explicativa no texto da lei, levantando mais dúvidas sobre o propósito desta classificação e sobre o formato de sua utilização. Segundo conversas com participantes do processo de elaboração do PDMF, a proposta das AUEs gerou tantas polêmicas que os artigos originais da proposta foram suprimidos na aprovação da lei final. Finalmente, as AUEs aparecem ainda na legislação dentro da seção de Urbanização Social como uma área onde deve ser garantida, pelo Município, a produção de habitação para a população com renda na faixa de zero a dez salários mínimos, com preços acessíveis, a partir de medidas e incentivos para realização de loteamentos, condomínios ou vilas.

Quando observamos as tabelas de limites de ocupação e de adequação de usos anexas ao PDMF, essas classificações das AUEs parecem contraditórias em alguns aspectos. Tais tabelas, que deveriam refletir o texto em normativas e índices, direcionam para a formação de uma área com densidade muito baixa. Nesse sentido, os índices da Tabela de Limite de Ocupação trazem uma taxa de ocupação máxima de $15 \%$, com limite de dois pavimentos e coeficiente de aproveitamento máximo de 0,1 , além de impedir o parcelamento e indicar uma densidade máxima de 15 habitantes por hectare. A Tabela de Adequação de Usos ainda proíbe vários tipos de comércio de pequeno porte, como loja de roupas, cosméticos, óticas, postos de gasolina, condomínio de salas comerciais e sede de unidades administrativas locais, entre outros. Frente à intenção de criação de novas centralidades e de promoção de mescla de funções, tais números e proibições parecem impossibilitar tal processo de 
desenvolvimento urbano, sendo necessária a elaboração de projeto específico para cada uma dessas áreas que altere esses parâmetros de seu zoneamento original.

De fato, tenta-se reverter essa situação em 2020 a partir da publicação do Decreto Municipal n. 21.974, que mantém a importância das AUEs como áreas que fortalecem a multicentralidade da cidade ao permitir o adensamento de porções ainda não ocupadas do terrítorio, enquanto mantém áreas de relevância ambiental e paisagística protegida. $O$ decreto ainda reafirma a diretriz do plano diretor de garantia da urbanização social em toda AUE. No entanto, o Art. 3 do Decreto altera diretamente a Lei 482/2014, ao permitir o parcelamento de AUE. Isso seria possível a partir da elaboração de um Plano Específico de Urbanização (PEU), também regulamentado por decreto (Decreto Municipal n. 21.688). Embora esses decretos prevejam a formação de grupos técnicos para analisar os projetos, sua composição é feita por membros da Prefeitura Municipal e um representante do interessado. Ainda são previstas consultas públicas para o desenvolvimento e debate de um programa de interesse com investimentos, mitigações e compensações ao projeto; e a manifestação do Conselho das Cidades antes do envio do projeto de lei à Câmara. Ainda assim, as AUEs aparecem como um "cheque em branco", sem limites de uso e índices urbanísticos, sujeitas ao debates específicos da instalação do seu PEU.

Finalmente, considerando que o Decreto Municipal n. 21.974 acerca da AUEs está alterando a Lei Complementar do Plano Diretor (Lei 482/2014), ainda em dezembro de 2020 dois vereadores por Florianópolis protocolaram o Projeto de Decreto Legislativo 02472/2021 apontando para a irregularidade da violação à hierarquia legal. Assim, o Decreto "usurparia competência do Poder Legislativo Municipal, afrontando-se o princípio fundamental da separação dos poderes, ou seja, trata-se de ato ilegal, nulo e passivel de ser sustado pelo Poder Legislativo" 5 . Nesse sentido, novo esforço de regulamentar tais questões em lei complementar ocorre em em 2021, com a proposta de alterar o PDMF e, entre outros, retirar os índices e parâmetros restritivos das AUEs nas tabelas anteriormente mencionadas.

Esse esforço acontece acrescentando novos capítulos ao conflituoso processo do plano diretor já relatado. Primeiro, um Projeto de Lei encaminhado à Câmara de Vereadores em janeiro de 2021 em caráter extraordinário, batizado de "Floripa Mais Empregos", propõe a revisão de inúmeros pontos do plano. Apesar de ter sido encaminhado por técnicos dos órgãos municipais, o projeto foi enviado

\footnotetext{
${ }^{5}$ Disponível em https://paperlessgov-editor.cmf.sc.gov.br/visualizador/publico/anexo/5148. Acessado
} em 21 de julho de 2021. 
diretamente à Câmara, sem discussões no Conselho da Cidade e abertura para manifestações públicas. Na Câmara, o projeto não teve votos suficientes para sua aprovação. Segundo, após a rejeição, uma nova proposta de revisão foi enviada ao Conselho da Cidade ainda em 2021 e também gerando polêmicas com relação ao processo adotado naquela instância, já que o tempo reduzido para análise e manifestações dos conselheiros também não foi acompanhado de debate e participação popular. Em novembro de 2021 o projeto de lei com a revisão do PDMF ainda não havia sido enviado novamente à Câmara.

A respeito das AUEs tal como definidas originalmente pelo PDMF de 2014, estão delimitados dez perímetros na cidade de Florianópolis, como visto na Figura $01^{6}$. Estas áreas apresentam uma ocupação de baixa densidade, algumas inclusive próximas a áreas rurais, como as AUEs de Ratones e Pântano do Sul. Porém, em sua maioria são adjacentes ou próximas a regiões consolidadas na malha urbana e com uma densidade maior, seguindo o propósito de zona de amortecimento entre a cidade consolidada e as áreas não urbanizadas das Macro Áreas de Transição mencionado acima. Percebe-se que elas também representam grandes porções de área no território, espalhadas por toda a extensão da parte insular do município, estando presentes em 6 dos 12 distritos de Florianópolis, conforme visto na Figura 02. características gerais e não o parcelamento do solo e sua propriedade. 
Figuras 01 e 02 - Localização das AUEs em Florianópolis e distritos com AUEs
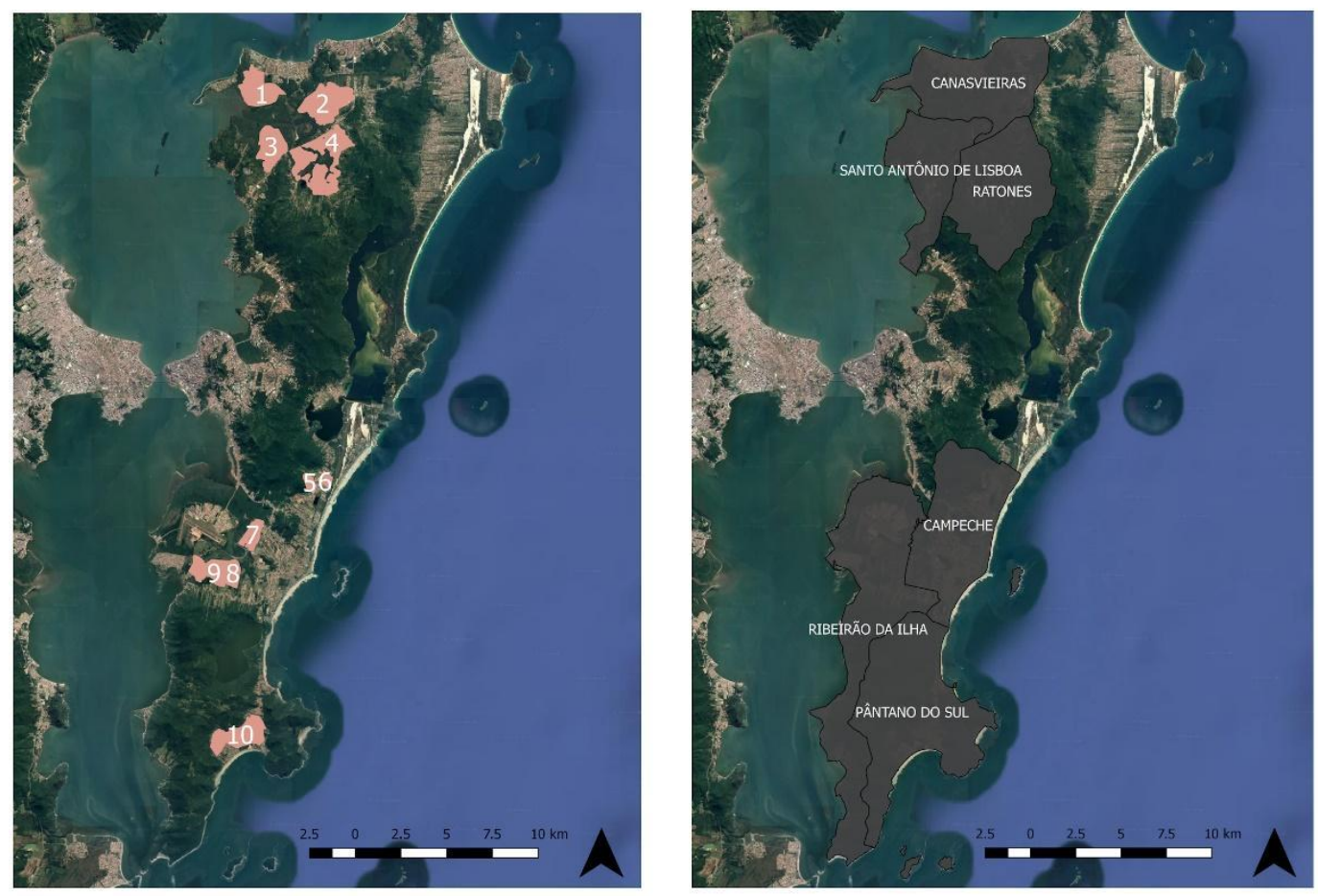

Fonte: Elaborado pelas autoras a partir de dados da PMF (2014) e Censo IBGE 2010. Fundo Google Satélite.

Nota-se ainda, como visto no Quadro 01, que várias AUEs englobam Áreas de Limitação Ambiental (ALAs), que são um outro tipo de AEIU, ou seja, áreas de intervenção urbanística especial como mencionado acima. Essas ALAs se subdividem em: (1) presença de vegetação considerável; (2) presença de banhados; e, (3) áreas tombadas ambientalmente. No caso das áreas zoneadas como AUE, a indicação de banhados é o tipo de limitação à ocupação mais frequente. Muitas das áreas também possuem cursos d'água de pequeno e grande porte, que devem ter suas matas ciliares preservadas. Ainda, a área indicada no Distrito do Ribeirão da Ilha possui extensas áreas de manguezais e banhados, assim como no Distrito de Canasvieiras, onde as AUEs se sobrepõem em parte à Reserva de Carijós, uma Estação Ecológica localizada no noroeste da llha e coordenada pelo Instituto Chico Mendes para proteção dos manguezais e restingas da bacia do Rio Ratones e do Saco Grande. Finalmente, no caso do Distrito de Ratones, existe a sobreposição de AUE com o maior rio do distrito, o Rio Ratones, que já vem sofrendo um intenso processo de assoreamento, e no Distrito do Pântano do Sul há a sobreposição com uma extensa área alagável. Esses exemplos mostram como a fragilidade ambiental nas AUEs impõe uma alta limitação de ocupação, tal qual previsto pelo PDMF e 
outras legislações de proteção ambiental, tornando conflituoso o processo de implantação de uma nova centralidade nessas áreas.

Quadro 01 - Caracterização das AUEs em Florianópolis

\begin{tabular}{|l|l|l|l|l|l|l|} 
AUE & $\begin{array}{l}\text { Área } \\
\text { (ha) }\end{array}$ & Distrito & $\begin{array}{l}\text { Tijpo de ALA } \\
\text { (Área de } \\
\text { Limitação } \\
\text { Ambiental)* }\end{array}$ & $\begin{array}{l}\text { Cursos } \\
\text { d'água de } \\
\text { grande } \\
\text { porte }\end{array}$ & $\begin{array}{l}\text { Cursos } \\
\text { d'água de } \\
\text { pequeno } \\
\text { porte }\end{array}$ & $\begin{array}{l}\text { AEIS (Áreas } \\
\text { Especiais de } \\
\text { Interesse } \\
\text { Social) }\end{array}$ \\
\hline $\mathbf{1}$ & 289,82 & Canasvieiras & 1 & Sim & Sim & Não \\
\hline $\mathbf{2}$ & 39,41 & Canasvieiras & 1 e 2 & Sim & Sim & Não \\
$\mathbf{3}$ & 254,11 & Santo Antônio & 2 & Sim & Sim & Não \\
\hline $\mathbf{4}$ & 528,69 & Ratones & 2 & Sim & Sim & Não \\
\hline $\mathbf{5}$ & 40,98 & Campeche & - & Não & Sim & Não \\
\hline $\mathbf{6}$ & 35,54 & Campeche & - & Não & Sim & Não \\
\hline $\mathbf{7}$ & 109,14 & Campeche & 1 e 2 & Não & Sim & Não \\
\hline $\mathbf{8}$ & 88,83 & Campeche & 1 & Não & Sim & Não \\
\hline $\mathbf{9}$ & 194,71 & Ribeirão da ilha & 1 e 2 & Sim & Sim & Sim \\
\hline $\mathbf{1 0}$ & 312,83 & Pântano do Sul & 1 e 2 & Sim & Sim & Não \\
\hline & & & & & &
\end{tabular}

Fonte: Elaborado pelas autoras a partir de dados da PMF (2014).

*ALA 1 - Vegetação; ALA 2 - Banhado; ALA 3 - Área Tombada

No Quadro 01 também é possível notar uma AUE coincidindo com a indicação de Áreas Especiais de Interesse Social (AEIS), que são áreas sobrepostas ao zoneamento geral da cidade para promover o incentivo à habitação de interesse social. Esta sobreposição está de acordo com a legislação, uma vez que o plano faz menção à urbanização social como um dos enfoques prioritários das AUEs, como mencionado anteriormente. Entretanto, apenas a AUE localizada no Distrito do Ribeirão da llha possui uma AEIS em parte do seu perímetro, deixando as demais áreas com poucos instrumentos para que essa urbanização social ache meios de se consolidar. Isso se faz importante visto que algumas das AUEs indicadas estão sujeitas a um rápido avanço do interesse imobiliário, em especial aquelas localizadas nos distritos de Ratones e Ribeirão da Ilha, devido a sua proximidade a projetos de empreendimentos de grande porte. É este o caso, por exemplo, do Condomínio Aeronáutico Costa Esmeralda em Ratones, que tem sua propaganda firmada na localização próxima ao bairro reconhecidamente de alta renda Jurerê Internacional, bem como do novo terminal do Aeroporto de Florianópolis no Ribeirão da Ilha, que será melhor tratado no tópico seguinte.

Finalmente, é importante destacar que três distritos apontados no Quadro 01 (Canasvieiras, Ratones e Ribeirão da Ilha) são indicados também como áreas prioritárias para realização de Operações Urbanas Consorciadas (OUCs) pelo plano diretor. As OUCs são um instrumento que, como previsto pelo Estatuto da Cidade, 
visa trazer melhorias sociais e valorização ambiental para áreas da cidade, alcançando transformações urbanísticas estruturais, com a participação conjunta da sociedade civil, proprietários e agentes imobiliários através da coordenação do Poder Público Municipal. No caso do plano diretor de Florianópolis, os estudos elaborados em 2013 antes da aprovação do plano, associavam esse instrumento às AUEs. Essa associação foi posteriormente consolidada no período de revisão do plano após sua judicialização, nas minutas de lei produzidas em 2016 e 2017, quando algumas dessas áreas zoneadas como AUEs são consideradas como sujeitas à operação urbana. Ainda, mesmo que no texto do plano aprovado em 2014 não exista correlação clara entre os dois instrumentos, os mapas anexos indicam o perímetro de apenas quatro das sete OUCs previstas, faltando justamente a delimitação para aqueles três distritos mencionados acima, onde estão também localizadas as AUEs. Ou seja, diante dessa associação recorrente entre os instrumentos e baseado em conversas com informantes, pode-se inferir que OUCs poderiam vir a ser instauradas nas AUEs, principalmente nos distritos prioritários identificados acima.

Mesmo assim, apesar da maioria das AUEs previstas no PDMF estarem próximas a áreas já urbanizadas, o fato de se caracterizarem prioritariamente como áreas sem ocupação, muitas vezes com infraestrutura e rede viária insuficientes e/ou pouco desenvolvidas, torna duvidoso o processo de realização de uma OUC já que o instrumento funda-se no interesse imobiliário ou particular que possa oferecer os recursos necessários para as transformações estruturais. Em uma OUC, a outorga de benefícios construtivos (como alterações de uso, potencial construtivo, regularização fundiária, entre outros) financia as obras públicas necessárias para completar o programa de ocupação e garante a sustentabilidade econômica do projeto. Enquanto muitos autores acusam as OUCs de serem operações imobiliárias (Maricato e Ferreira, 2002), fica claro que o instrumento somente funciona com a ação de proprietários e agentes imobiliários. A possibilidade de grandes áreas com certo isolamento espacial, grande fragilidade ambiental e baixo potencial construtivo virem a atrair esse interesse privado torna nebulosa a relação entre as AUEs e o instrumento OUC. Por outro lado, naquelas áreas nas quais já existe o interesse do mercado imobiliário, como no caso do Distrito de Ratones e do Distrito do Ribeirão da Ilha mencionados acima, a implantação dessas OUCs pode vir a concentrar recursos e causar a expulsão de grupos mais vulneráveis, caso não sejam implementadas medidas que garantam a sua permanência no local (Siqueira, 2014). 
A relação entre AUEs, PEUs e OUCs, portanto, expõe a intenção de propor algum instrumento de implementação de grandes projetos urbanos para essas áreas e enfatiza a necessidade de um projeto de cidade que faça a conexão entre esses instrumentos com os objetivos gerais do desenvolvimento de Florianópolis. Justamente, a crítica à tradição modernista de planos diretores abrangentes e ambiciosos, mas que não eram implementados e que resultaram em um crescimento insustentável voltado apenas para parte de seus habitantes, gerou a ênfase do planejamento urbano contemporâneo nos grandes projetos urbanos (Smolka e Lungo, 2002 e 2005). Em contraste com o plano diretor, essa escala intermediária de atuação busca abordar os problemas, particularidades e oportunidades de um recorte territorial de maneira mais contextual e contando com participação da sociedade civil.

Entretanto, além das inseguranças políticas e jurídicas do plano diretor de Florianópolis, o PDMF e os decretos posteriores tornam duvidosa a maneira como este grande projeto poderia vir a se instaurar em uma AUE. A sua curta definição, a associação com diferentes instrumentos e objetivos, os índices urbanísticos atualmente indicados, aliadas às dúvidas quanto aos benefícios e as contrapartidas esperadas dos proprietários para a obtenção de um bem coletivo maior, trazem o questionamento da suficiência de tal zoneamento para a obtenção dos resultados que almeja. É nesse sentido que pode ser realizada a análise da AUE prevista no Distrito do Ribeirão da llha, como se verá a seguir.

\section{A AUE no Distrito do Ribeirão da llha: uma área sem definição clara de projeto}

As diversas porções da cidade zoneadas como AUEs, vistas anteriormente, estão associadas aos objetivos de diminuição da dependência do Distrito Sede e de criação de novos núcleos de desenvolvimento urbano nos diversos distritos de Florianópolis. É importante destacar, portanto, que o zoneamento do PDMF não foi direcionado para uma região específica, como ocorreu durante muitos anos com a concentração de investimentos no Distrito Sede e norte da llha. Pelo contrário, se distribuiu para áreas que estiveram historicamente fora do foco principal de atuação do poder público. Esse é justamente o caso do sul da ilha, que vem apresentando um grande crescimento populacional e turístico nas últimas décadas. É neste contexto que se encontra a AUE do Distrito do Ribeirão da llha (Figura 03). 
Figura 03 - Zoneamento do PDMF e a AUE Ribeirão da Ilha

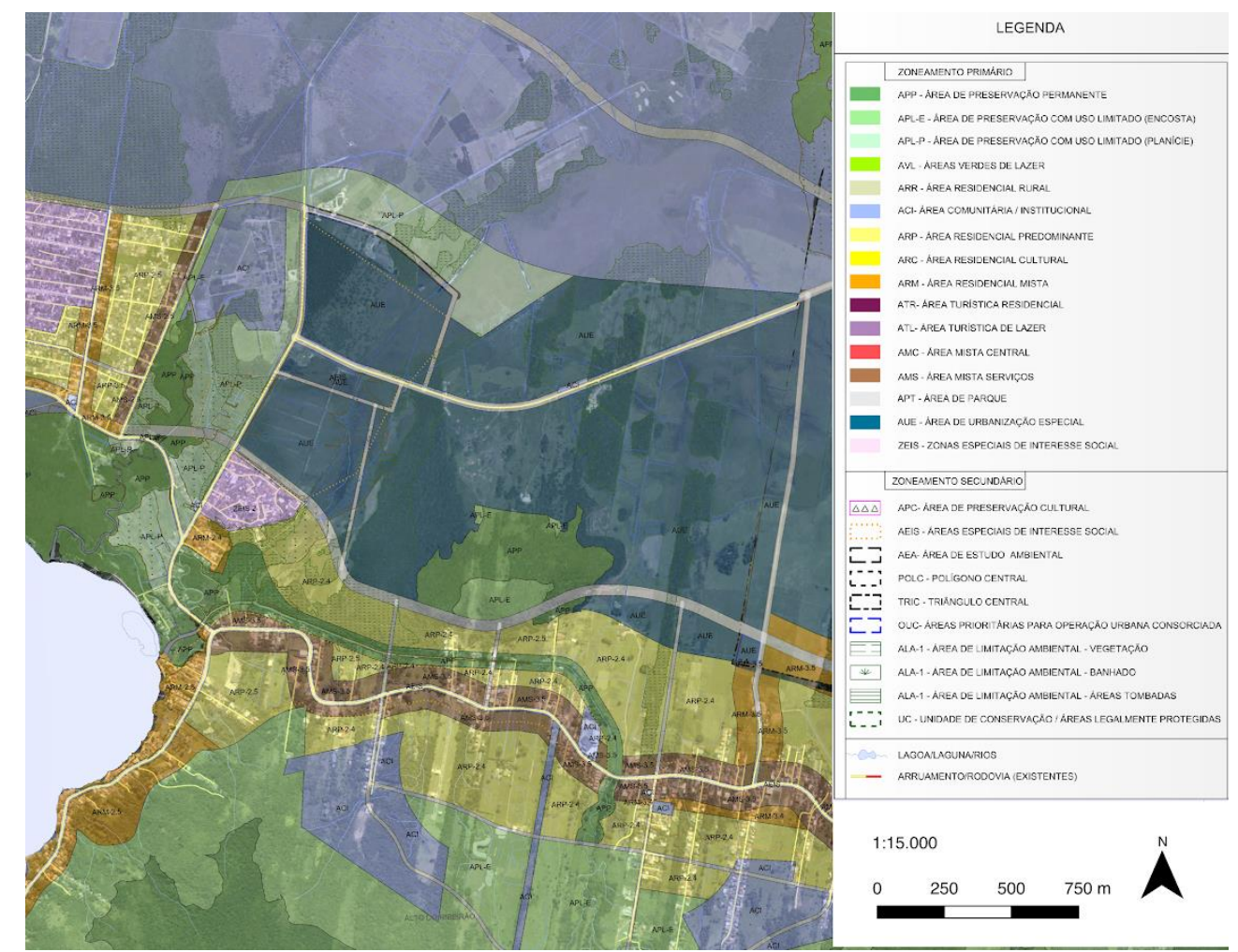

Fonte: Adaptado pelas autoras a partir de PMF (2014).

A AUE do Ribeirão da llha encontra-se logo na entrada do Distrito, em sua porção nordeste, ocupando uma área total de 194,71 hectares que se limita com outra AUE do distrito vizinho, Campeche, formando assim uma grande mancha na cidade com este tipo de zoneamento às margens da Rodovia Aparício Ramos Cordeiro, uma das entradas para o sul da ilha (Imagens 03 e 04). A AUE do Ribeirão conforma-se como uma área majoritariamente plana e possui limites com Áreas de Proteção de Uso Limitado de Planície (APL-P) e Encosta (APL-E), assim como Áreas de Preservação Permanente. Neste perímetro existem também algumas Áreas de Limitação Ambiental de vegetação e banhado, além de cursos d'água com matas ciliares preservadas, indicando a presença de ecossistemas sensíveis. 
Figura 04 - Parcelamento e uso do solo na AUE Ribeirão da llha

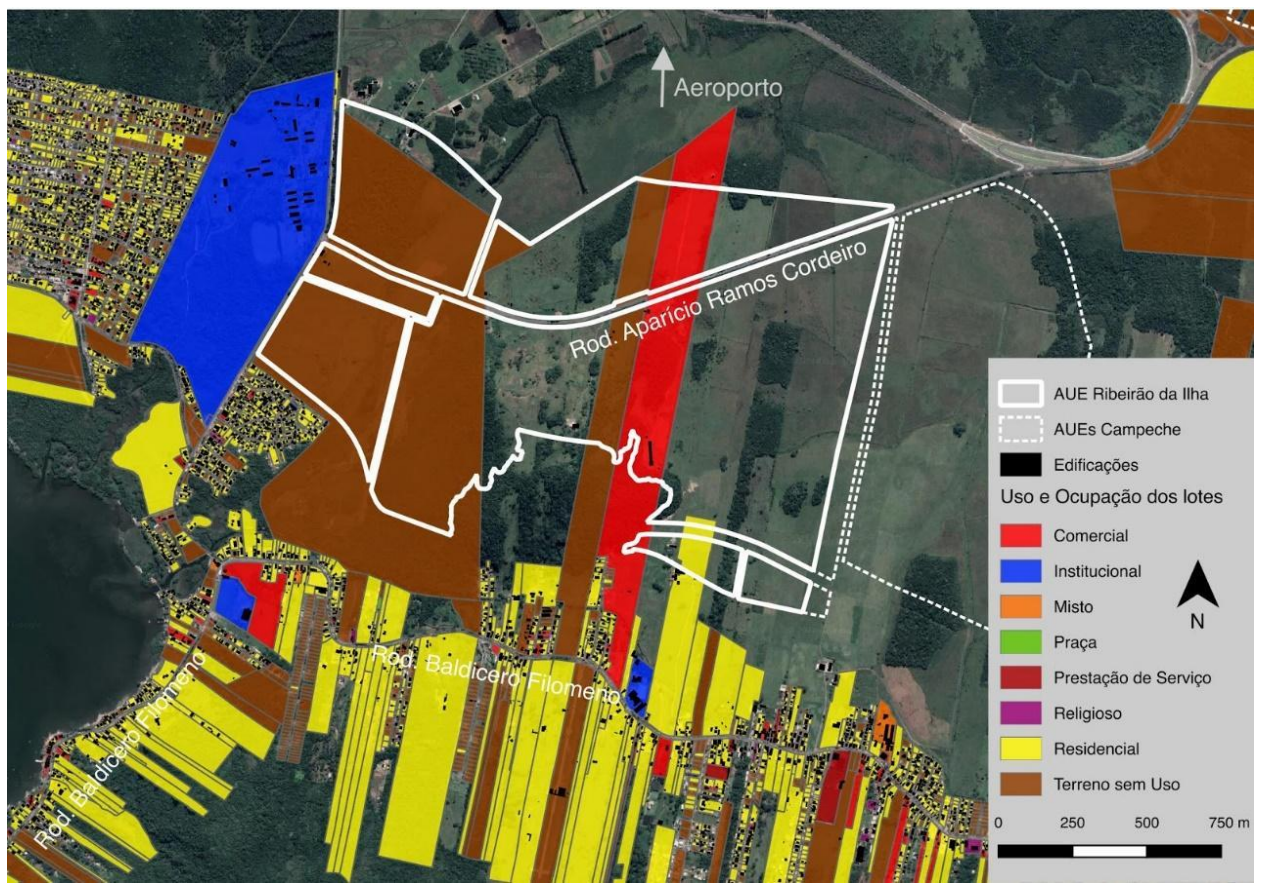

Fonte: Elaborado pelas autoras a partir de PMF (2012 e 2014), fundo Google Satélite.

A proximidade da AUE com o Aquífero do Campeche traz à tona mais uma questão relacionada à preservação ambiental. Com volume estimado de 105 bilhões de litros de água e cerca de 40 metros de profundidade, o Aquífero é perfurado por 11 poços para a captação das águas subterrâneas para ser utilizado como parte do abastecimento da região leste e sul da cidade de Florianópolis (BORGES, 1996). Por ser poroso e ter uma recarga proveniente exclusivamente de águas pluviais, 0 Aquífero é vulnerável a contaminações, fazendo-se necessário um monitoramento do crescimento da urbanização do local acompanhado de estudos de impacto ambiental, incluindo a previsão de um sistema de saneamento eficiente. A importância ambiental da área é tão marcante que, durante o processo de reelaboração do plano diretor ocorrido em 2016 após sua judicialização, as minutas e os mapas de zoneamento em discussão mostravam toda a área que hoje constitui a AUE zoneada como uma Área de Preservação de Uso Limitado de Planície, tendo baixas taxas de ocupação e impossibilitando o parcelamento do solo.

Além dos aspectos ambientais dessa AUE, é importante destacar a relevância cultural do Ribeirão. O Distrito do Ribeirão da llha é um dos mais antigos de Florianópolis, tendo sua ocupação sido iniciada em 1756 com a vinda de casais açorianos para a llha de Santa Catarina. A Freguesia do Ribeirão tem o traçado urbano original do século XVIII preservado conforme os moldes coloniais (Pereira, 1990) e, além do patrimônio construído, outras atividades tradicionais realizadas no 
Distrito (como pesca artesanal, construção de embarcações baleeiras, confecção de rendas de bilro e festas tradicionais, entre outras) fazem parte do rico patrimônio imaterial do Ribeirão e da cidade como um todo. O Distrito, que acompanhava o ritmo lento de crescimento da cidade, passou a ter seu enfoque econômico voltado para o turismo e a gastronomia tradicional principalmente a partir das décadas de 1970 e 1980, tornando-se alvo do avanço do capital imobiliário e sofrendo alterações socioeconômicas e espaciais (Nór, 2010; Siqueira, 2008). É neste período também que as conexões viárias com o centro da cidade começaram a ser consolidadas.

A ocupação do Distrito se deu principalmente ao longo de uma via, a Rodovia Baldicero Filomeno, conformando um traçado longitudinal com lotes de pequena testada e grande comprimento, causando problemas de mobilidade e conectividade. Já a rodovia que divide a AUE ao meio (Rodovia Aparício Ramos Cordeiro) foi construída em período mais recente, passando por áreas ainda não ocupadas, cortando os fundos destes lotes estreitos e compridos e tendo inclusive grandes áreas com propriedades e/ou parcelamento do solo ainda não delimitado, podendo ser resquícios das já mencionadas terras comunais ou devolutas. A delimitação da AUE não coincide com o limite dos lotes, que em sua maioria são terrenos sem uso urbano e/ou permanente. São majoritariamente de usos rurais ou não definidos especificamente, como galpões e depósito de lixo, com poucas construções existentes e de padrão simples, isoladas no lote, cercadas por grande área verde. A baixa densidade da área contrasta com o número de habitantes e domicílios do entorno mais ocupado, incluindo grandes terrenos de uso institucional pertencentes à Universidade Federal de Santa Catarina (UFSC), uma Zona Especial de Interesse Social (ZEIS) e áreas que sofreram e vem sofrendo uma densificação populacional.

Entre essas áreas do entorno que vêm apresentando crescimento é importante destacar: (1) a Tapera, área de ZEIS que caracteriza-se também como um dos assentamentos subnormais do município (IBGE, 2010); (2) o Alto Ribeirão, bairro tradicional e alvo de recente valorização imobiliária com o surgimento de loteamentos e condomínios de médio e alto padrão e, (3) a região de Carianos, que teve seu desenvolvimento urbano incentivado com a vinda do Aeroporto Internacional Hercílio Luz em 1975 para a região. Estas áreas representam a principal fonte do crescimento populacional do Distrito, que praticamente dobrou o número de residentes (crescimento de 93\%) entre os anos de 1991 e 2010, de acordo com o IBGE, e deve ter aumentando ainda mais na década seguinte. Esse crescimento populacional no entorno da AUE traz à tona a questão da valorização 
que a região vem sofrendo, com aumento do padrão das edificações residenciais e um aumento do poder aquisitivo de parcela dos moradores, enquanto existem áreas de grande vulnerabilidade socioeconômica.

Outro importante fator que impulsiona a valorização da área é a construção do novo terminal do Aeroporto de Florianópolis nas proximidades, inaugurado em setembro de 2019. Por um lado, as reformas viárias decorrentes do mesmo, que criam um novo acesso tanto para o terminal quanto para o sul da ilha, pretendem funcionar como alternativa às rodovias preexistentes. Por outro, a criação do novo terminal, quatro vezes maior do que o anterior e com capacidade para 8 milhões de passageiros, é há muito esperada pelo poder público e pelos habitantes de um município que se promove nacional e internacionalmente na atividade turística. Isso demonstra os interesses tanto públicos quanto privados aos quais o Distrito têm sido submetido e que se tornaram ainda mais evidentes com o término das obras do aeroporto e o grande fluxo de pessoas gerado pelo mesmo.

Um novo padrão de vida, portanto, vem se instaurando aos poucos no Distrito, seguindo os avanços dos interesses públicos e privados e modificando o perfil socioeconômico local (Siqueira, 2008). Os bairros do Ribeirão originalmente possuíam a maior parte de sua população de renda média-baixa; os comércios de pequeno porte; e pouca oferta de espaços de cultura e lazer. Novos loteamentos, comércios e serviços vêm alterando esse padrão. Nesse sentido, deve-se também alertar para o atual risco que a valorização imobiliária acarreta frente à demanda por moradia nas áreas de ZEIS, já bastante densificadas antes mesmo do desenvolvimento da AUE. Ou seja, existe o risco de gentrificação da área. Embora o PDMF de 2014 indique também uma Área Especial de Interesse Social em parte da delimitação, como existem poucos parâmetros estabelecidos tanto para as AUEs quanto para as áreas de interesse social, corre-se 0 risco da falta de representatividade da população local e de sua participação no futuro desenvolvimento da área. 
Figuras 05 e 06 - As tipologias que conformam o Distrito e seus diferentes padrões socioespaciais
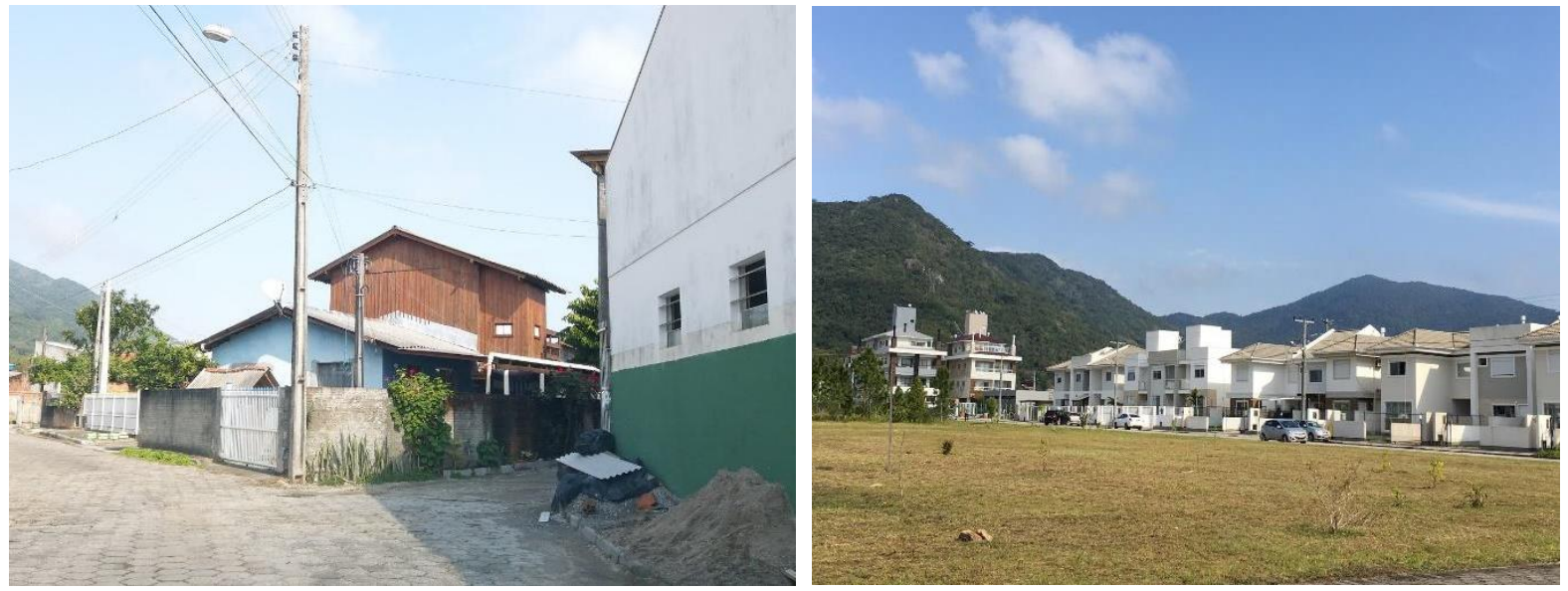

Fonte: Acervo da pesquisa.

Finalmente, de acordo com o PDMF 2014, existe a previsão de uma OUC para o Distrito do Ribeirão da Ilha, ainda sem perímetro delimitado em mapa. Como já mencionado na seção anterior, após a análise dos documentos institucionais e conversas com agentes envolvidos no planejamento urbano local, deve-se considerar a possibilidade de que a OUC se sobreponha à zona da AUE, trazendo assim a importância da atuação do mercado imobiliário para o desenvolvimento do projeto local. De forma a alavancar esse processo, ainda temos os decretos de 2020 vinculando as AUEs aos PEUs. É importante relembrar que, atualmente, a Tabela de Limite de Ocupação do PDMF traz uma taxa de ocupação máxima de 15\%, com limite de dois pavimentos e coeficiente de aproveitamento máximo de 0,1 , impede 0 parcelamento e indica uma densidade máxima de 15 habitantes por hectare, além de proibir diversos usos de pequeno porte conforme a Tabela de Adequação de Usos, como loja de roupas, cosméticos, óticas, postos de gasolina, condomínio de salas comerciais, sede de unidades administrativas locais, entre outros.

Considerando as limitações presentes na legislação atual, a elaboração da OUC e/ou do PEU e seu plano de ocupação poderiam reverter a atual situação de "congelamento" da área. Surgem, então, questões para o futuro da área: como aliar as problemáticas sociais e coletivas neste grande projeto urbano, visto a diversidade de agentes que o compõem, fazendo prevalecer o interesse coletivo? Como integrar a questão ambiental, tão forte e significante na definição da AUE no texto do plano, com uma crescente densificação e valorização da área específica da AUE do Distrito do Ribeirão da Ilha? A AUE, tal como apresentada pelo PDMF de 2014 e os decretos posteriores, não deixa claro como tais objetivos poderiam ser atingidos. 
Áreas complexas, porém com grande potencialidade, caracterizam os locais zoneados como AUEs. A AUE do Ribeirão da llha revela uma confluência de interesses e possibilidades que, a depender das atitudes e do planejamento realizado, poderia vir a se transformar em uma nova centralidade dos bairros do entorno. Entretanto, a atual falta de parâmetros para ocupação e as poucas oportunidades de participação social configuram hoje as AUEs como áreas à espera de definições e projetos que deem conta de sua complexidade e tragam benefícios para a cidade como um todo, de maneira socialmente inclusiva e ambientalmente responsável.

\section{Considerações Finais}

As Áreas de Urbanização Especial, como apresentadas na Lei 482 de 2014, o Plano Diretor vigente em Florianópolis, representam uma oportunidade para balancear o desenvolvimento urbano local. Em primeiro lugar, destacam-se as extensas áreas ainda não ocupadas na cidade, seja devido à presença de porções do território que devem ser protegidas ambientalmente, seja devido a um histórico de planejamento que priorizou outras partes da cidade. Nesse sentido, as AUEs poderiam propor ocupações para essas áreas como um projeto de transição com a cidade consolidada. Segundo, a forma como se deu o desenvolvimento de Florianópolis tornou a mesma dependente da oferta de serviços e equipamentos que se concentraram no Distrito Sede, causando intensos problemas de mobilidade urbana e distanciando os vários núcleos populacionais tradicionais do processo de formação da cidade e de seu potencial concentrador da vida urbana. Essa dependência tornou-se ainda mais marcante com o processo de segregação socioespacial vivido nas últimas décadas e o crescimento de comunidades informais com condições precárias de habitabilidade. Portanto, a indicação de novas centralidades que consideram a riqueza ambiental e incluem a urbanização social podem ser consideradas uma conquista do PDMF de 2014, apesar de seu conturbado processo de realização.

Por outro lado, a maneira pela qual os benefícios sociais e ambientais pretendidos com as AUEs serão obtidos não é delineada de forma clara pelo texto do plano. Definições amplas e conflitos de categorização, além de índices pouco compatíveis com as intenções de formação de uma nova centralidade marcam o texto do PDMF. As novas regulamentações pelos decretos de 2020 trazem novas 
definições, tornando as AUEs como áreas de desenvolvimento preferencial na cidade e regulamentando o processo de realização dos PEUs. No entanto, além de serem insuficientes como estímulo à urbanização e para que se faça valer a sua intenção de proteção ambiental e urbanização social, não estabelecem qualquer limite ou contrapartida esperada pelos projetos, abrindo espaço para discricionariedade e falta de transparência. Ainda, são também considerados por alguns agentes como ilegais e, portanto, abertos à contestação visto que alteram leis complementares vigentes e foram formulados sem participação popular.

Ao longo desta pesquisa também foi identificada a possibilidade da implementação de operações urbanas nessas áreas. Entretanto, a complexidade da aplicação do instrumento, a necessidade de mecanismos de atração do mercado imobiliário e proprietários para adesão ao projeto em áreas ainda não ocupadas e os resultados excludentes apresentados em experiências prévias com operações urbanas em outros municípios brasileiros, geram dúvidas sobre a sua aplicação local. O mecanismo de uma OUC exige uma grande capacidade administrativa, de negociação e de realização por parte do município, característica que a cidade Florianópolis não demonstrou ao longo do desenvolvimento do seu último plano diretor. Sendo assim, o panorama atual expõe os territórios tanto das OUCs quanto das dez AUEs indicadas em um estado de espera, não tendo sofrido nenhuma transformação considerável desde a primeira aprovação do plano em lei, em janeiro de 2014.

As AUEs de Florianópolis, portanto, estão inseridas em um contexto de rediscussão da política urbana brasileira. Os planos diretores pós-Estatuto da Cidade demonstram um rico debate sobre as nossas cidades e o aprendizado sobre instrumentos mais sensíveis à realidade local e que conjugam interesses públicos e privados. A sua capacidade de implementação, entretanto, ainda parece muito aquém do desejado. O longo e conflituoso processo de elaboração do PDMF de 2014 demonstra problemas no cumprimento dos princípios do planejamento e gestão democrática das cidades, reafirmado com as novas proposições de alterações no plano em 2021. Ainda, o texto da lei vigente expõe essas dificuldades com partes contraditórias, instrumentos pouco definidos e seções simplesmente inexistentes. Este é justamente o caso das AUEs.

Com uma definição que aborda aspectos ambientais, sociais e de balanceamento do desenvolvimento polinucleado da cidade, existe pouca clareza sobre o seu funcionamento. Enquanto o zoneamento atual funciona como uma trava 
limitando usos e ocupação, essas áreas permanecem congeladas e à espera de um projeto específico a ser desenvolvido. Entretanto, também não há indicações sobre como desenvolver projetos que atinjam os objetivos delineados ou ampliar a participação social. Enquanto isso, Florianópolis continua crescendo e, com o seu território cada vez mais disputado para ocupação, a pressão sobre tais áreas tornase cada vez mais significativa, assim como as preocupações com o seu futuro. Portanto, mesmo com a aprovação de novos planos pós-Estatuto da Cidade, para que seus princípios não recaiam na mesma trajetória de seus predecessores, pouco efetivos e implementados somente no que interessa às elites políticas e econômicas, é necessário fortalecer os processos participativos e seus instrumentos, com uma melhor definição dos benefícios e contrapartidas esperadas dos agentes envolvidos no desenvolvimento urbano local.

\section{REFERÊNCIAS}

BASSUL, J. R. Reforma urbana e Estatuto da Cidade. EURE (Santiago), Santiago, v. 28, n. 84, 133-144, 2002.

BÓRGES, S. F. Características hidrquímicas do aqúífero freático do Balneário Campeche, ilha de Santa Catarina-SC. 1996. 81 f. Dissertação (Mestrado em Geografia). Centro de Filosofia e Ciências Humanas, Universidade Federal de Santa Catarina, Florianópolis, 1996.

CAMPOS, N. J. Terras comunais na Ilha de Santa Catarina. Florianópolis: Editora da UFSC/ Fundação Catarinense de Cultura Edições, 1991. 162p.

CUNHA, Luis Felipe. A esfera pública e o Plano Diretor Participativo de Florianópolis. 2013. 181 f. Dissertação (Mestrado) - Curso de Geografia, Universidade Federal de Santa Catarina, Florianópolis, 2013. Disponível em:

https://repositorio.ufsc.br/xmlui/handle/123456789/122922. Acesso em: 17 jun. 2020.

IGOR, Renato. Proposta de mudança no Plano Diretor de Florianópolis provoca reações. Florianópolis: NSC Total, 19 de janeiro de 2021. Disponível em: $<$ https://www.nsctotal.com.br/colunistas/renato-igor/proposta-de-mudanca-no-plano-diretorde-florianopolis-provoca-reacoes $>$.

INSTITUTO DE PLANEJAMENTO URBANO DE FLORIANÓPOLIS (IPUF). Formação Natural. Florianópolis, p.32. Disponível em:

<https://parquemunicipalmacicodacosteira.files.wordpress.com/2010/05/atlas_ipuf.pdf>. Acesso em: 01 novembro de 2018.

LUNGO, M.; SMOLKA, M. Macroproyectos urbanos: desafíos para las ciudades latinoamericanas. Land Line Newsletter, Lincoln Institute, v. 14, n. 4, 2002.

LUNGO, M.; SMOLKA, M. Land value and large urban projects: the Latin American experience. Land Line Newsletter, Lincoln Institute, v. 17, n. 1, 2005. 
MARICATO, E. As ideias fora do lugar e o lugar fora das idéias: planejamento urbano no Brasil. In: Arantes, Otília; Vainer, Carlos; Maricato, Ermínia, orgs. A cidade do pensamento único: desmanchando consensos. Petrópolis: Vozes, 121-192, 2000.

NÓR, S. Paisagem e lugar como referências culturais: Ribeirão da llha - Florianópolis. 2010. 231 f. Tese (Doutorado em Geografia). Centro de Filosofia e Ciências Humanas, Universidade Federal de Santa Catarina, Florianópolis, 2010.

PAIVA, E.; RIBEIRO, D.; GRAEFF, E. Florianópolis: Plano Diretor. Porto Alegre: Imprensa Oficial do Estado do Rio Grande do Sul, 1952.

PELUSO JÚNIOR, V. A. Aspectos geográficos de Santa Catarina. Florianópolis:

Fundação Catarinense de Cultura Edições/Editora da UFSC, 1991.

PEREIRA, E. A importação de conceitos modernistas no planejamento urbano de Florianópolis. In: VI Seminário de História da Cidade e do Urbanismo, 2000, Natal. Anais do VI Seminário de História da Cidade e do Urbanismo, 2000.

PEREIRA, N. V.; PEREIRA, F. V.; NETO, W. J. S. Ribeirão da Ilha - Vida e Retratos: Um distrito em destaque. Florianópolis: FFC, 1990.

PIMENTA, M. C. A. (org.). Florianópolis do outro lado do espelho. Florianópolis: Editora da UFSC, 2005.

PMF - Prefeitura Municipal de Florianópolis. Lei Complementar n. 482, de 17 de janeiro de 2014. Disponível em:<http://planodiretorflorianopolis.webflow.io/>. Acesso em 12 de novembro de 2014.

PMF - Prefeitura Municipal de Florianópolis. Decreto n. 21.688, de 26 de junho de 2020. Disponível

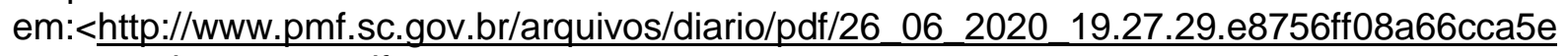
166a235d6097e38.pdf >

PMF - Prefeitura Municipal de Florianópolis. Decreto n. 21.974, de 11 de setembro de 2020. Disponível em:

<http://www.pmf.sc.gov.br/arquivos/diario/pdf/11 $092020 \quad 20.49 .07 .46255$ ed5228fb100c08 9b3b5ddfadc9b.pdf $>$

REDAÇÃO ND. Vereadores rejeitam projeto para alterar plano diretor de Florianópolis. Florianópolis: 27 de janeiro de 2021. Disponível em: <https://ndmais.com.br/politicasc/camara-projeto-plano-diretor-florianopolis/>.

REIS, A. F. Permanências e transformações no espaço costeiro: formas e processos de crescimento turístico na Ilha de Santa Catarina. 2002. 287 f. Tese (Doutorado em Estruturas Ambientais Urbanas) - Faculdade de Arquitetura e Urbanismo, Universidade de São Paulo, São Paulo, 2002.

RIZZO, P. M. B. Do urbanismo ao planejamento urbano: utopia e ideologia: caso de Florianópolis, 1950 a 1990. 119 f. 1993. Dissertação (Mestrado em Geografia) - Centro de Filosofia e Ciências Humanas, Universidade Federal de Santa Catarina, Florianópolis, 1993.

RIZZO, P. M. B. O planejamento urbano no contexto da globalização: caso do Plano Diretor do Campeche em Florianópolis-SC. Tese (Doutorado em Geografia) - Centro de Filosofia e Ciências Humanas, Universidade Federal de Santa Catarina, Florianópolis, 2013. 
SABOYA, R. PD Florianópolis: crônica de uma morte anunciada. Disponível em: $<$ http://urbanidades.arq.br/2010/04/pd-florianopolis-cronica-de-uma-morte-anunciada/>. Acesso em: 25/10/2018.

SIQUEIRA, M. Entre a prática e o discurso: a formação de espaços simbólicos na Florianópolis contemporânea. Dissertação (mestrado). Faculdade de Arquitetura e Urbanismo - USP, São Paulo, 2008.

SIQUEIRA, M. Entre o fundamental e o contingente: dimensões da gentrificação contemporânea nas operações urbanas em São Paulo. Cadernos Metrópole, v. 16, n. 32 , 391-415, 2014.

SIQUEIRA, M; CHAVES, L.; GONÇALVES, A. O desafio da participação popular no planejamento urbano brasileiro: o caso do Plano Diretor de Florianópolis. Revista Brasileira de Direito Urbanístico, ano 6, n. 11, p. 37-61, 2020.

SUGAI, M. I. As intervenções viárias e as transformações do espaço urbano: a via de contorno norte-ilha. Dissertação (mestrado). Faculdade de Arquitetura e Urbanismo USP, São Paulo, 1994.

SANTOS Jr., O.; MONTANDON, D. (Orgs.). Planos diretores municipais pós Estatuto da Cidade: balanço crítico e perspectivas. Rio de Janeiro: Letra Capital, 2011.

VEIGA, E. V. Florianópolis: memória urbana. Florianópolis: Editora da UFSC/Fundação Catarinense de Cultura Edições, 1993.

VILLAÇA, F. Uma contribuição para a história do planejamento urbano no Brasil. In: Deák, Csaba; Schiffer, Sueli Ramos, orgs. O processo de urbanização no Brasil. São Paulo: Edusp, 2004.

\section{NOTAS DE AUTOR}

\section{CONTRIBUIÇÃO DE AUTORIA}

Marina Toneli Siqueira - Concepção. Aquisição de financiamento, Metodologia, Administração do projeto, Supervisão, Validação, Análise de dados, Elaboração do manuscrito, revisão e aprovação da versão final do trabalho. Participação ativa da discussão dos resultados.

Carolina Silva e Lima Schleder - Concepção. Coleta e análise de dados, Elaboração do manuscrito, revisão e aprovação da versão final do trabalho. Participação ativa da discussão dos resultados.

Isabella Magnanti - Concepção. Coleta e análise de dados, Elaboração do manuscrito, revisão e aprovação da versão final do trabalho. Participação ativa da discussão dos resultados.

\section{FINANCIAMENTO}

Projeto de pesquisa financiado pelo Edital Universal CNPq 2016 Processo 427240/2016-6 e com bolsa $\mathrm{PIBIC/CNPq/UFSC.}$

\section{CONSENTIMENTO DE USO DE IMAGEM}

Não se aplica.

\section{APROVAÇÃO DE COMITÊ DE ÉTICA EM PESQUISA}

Projeto de pesquisa aprovado no Comitê de Ética em Pesquisa com Seres Humanos da Universidade Federal de Santa Catarina, Número do Parecer: 3.526.748.

CONFLITO DE INTERESSES

Não se aplica.

\section{LICENÇA DE USO}

Este artigo está licenciado sob a Licença Creative Commons CC-BY. Com essa licença você pode compartilhar, adaptar, criar para qualquer fim, desde que atribua a autoria da obra. 
HISTÓRICO

Recebido em: 04-06-2020

Aprovado em: 10-06-2021 